\title{
Electromagnetic Pollution of the Environment Due Leakage Radiation from Microwave Ovens
}

\author{
DIANA E. PANAIT ${ }^{1}$, ANDREEA C. JUFA ${ }^{1}$, LAURA FLOROIAN ${ }^{2}$, ALINA M. PASCU ${ }^{1}$, MIHAELA BADEA ${ }^{1 *}$, MARIA POPA ${ }^{3}$, \\ EUGEN-VICTOR MACOCIAN ${ }^{4}$, GABRIELA CIOCA ${ }^{5 *}$, SIMONA BUNGAU ${ }^{6}$ \\ ${ }^{1}$ Transilvania University of Brasov, Faculty of Medicine, Department of Fundamental, Prophylactic and Clinical Disciplines, 56 \\ Nicolae Balcescu Str., 500019, Brasov, Romania \\ ${ }^{2}$ Transilvania University of Brasov, Faculty of Electrical Engineering and Computer Sciences, Department of Automatic and \\ Information Technology, 29 Eroilor Blvd., 500007, Brasov, Romania \\ ${ }^{3} 1$ Decembrie 1918 University, Faculty of Economy Sciences, Department of Business Administration and Marketing, 15-17 Unirii \\ Str., 510009, Alba Iulia, Romania \\ ${ }^{4}$ University of Oradea, Faculty of Sciences, Physics Department, 1 Universitatii Str., 410087, Oradea, Romania \\ ${ }^{5}$ Lucian Blaga University of Sibiu, Faculty of Medicine, 10 Victoriei Blvd., 550024, Sibiu, Romania \\ 6University of Oradea, Faculty of Medicine and Pharmacy, Pharmacy Department, 29 Nicolae Jiga Str.,410028, Oradea, Romania
}

\begin{abstract}
This study compares the values of the electromagnetic fields generated by three types of microwave ovens with the values available in scientific literature, guides and protocols, considering their impact on human health. Variations in electromagnetic radiation have been determined during and outside the operating time of the microwave ovens at different distances from the oven and in different positions, thereof. The obtained data show higher values of the radiation leakage during operation than those provided by the regulations in force, for all types of studied ovens. The results of the study suggest the need to reduce the time spent near these devices and to optimize the equipment in order to reduce these radiation leakages.
\end{abstract}

Keywords: microwave oven, electromagnetic field, radiation leakage, electromagnetic pollution, human health

Microwaves are electromagnetic waves with higher frequencies than those of radio waves and lower than those of the infrared band. In the electromagnetic spectrum their frequencies occupy the portion between $300 \mathrm{MHz}$ to 300 $\mathrm{GHz}$, with wavelengths in an interval that varies from $1 \mathrm{~m}$ to $0.1 \mathrm{~cm}[1-3]$. They are used in a wide range of /domains such as communication (mobile phone networks-GSM, broadcasting and telecommunication transmissions, Bluetooth and Wi-Fi, satellite communications systems), navigation (Global Positioning System-GPS), RADAR (air traffic control, navigation of ships, weather forecasting, speed limitenforcement), radio astronomy and one of the most popular - heating and power application (microwave ovens, solar power satellite systems) [4-10].

There are certain electromagnetic fields that influence our lives in different ways, from the electromagnetic field the earth emits [11] to the electromagnetic fields attributed to all products surrounding us intended to make our live easier. All these have ultimately a cumulative effect that must be recognized and treated accordingly, in order to prevent health issues [12].

Scientific literature brings a lot of evidences on how radiation determined by broadcast television, radio communication and other domestic products such as microwave ovens, televisions and display screen equipment interfere with the human health [13]. Humans, among other living organisms, use internal bioelectrical signals that regulate most of the processes taking place continuously in their system. Electromagnetic fields are known to influence the way of transmission of these bioelectrical signals, determining thus alterations that may cause appearance of different pathologies [14].

The method on which the isolation of a microwave oven works is based on the Faraday's cage principle. It thus, seems clear that due to the fact that most of the microwave ovens have a glass door, the cage is not a perfect one, leading to necessity of use of other mechanism to trap the electromagnetic waves that otherwise would escape the oven. Measurements made in the scientific literature quote a time needed for the decay of the field that the microwave oven emits. When there is food inserted inside, the time in which the microwaves will remain in the cooking chamber is only $45 \mathrm{~ns}$ - as no human is able to handle the oven so fast, there is little risk involved regarding negative effects of captive microwaves [15].

Legislation available nowadays worldwide differs in terms of allowed exposure limits. Canada describes reference values for both controlled and uncontrolled environment. The electric field reference level measures $83 \mathrm{~V} / \mathrm{m}$ in uncontrolled environment and $170 \mathrm{~V} / \mathrm{m}$ in a controlled one as mentioned in the Safety Code 6 [16]. US Food and Drug Administration mention in their brochure on microwave ovens that in a good condition a microwave oven will not leak microwaves [17]. Federal standard 21 CFR 1030.1 states the limit of 5 milliwatts per square centimeter $\left(\mathrm{mW} / \mathrm{cm}^{2}\right)$ of microwave radiation at a distance of approximately 2 inches from the oven surface as being accepted for humans [17].

Our study aims to determine the level of radiations which household microwave oven determines both at rest and when functioning. These levels can further be compared to the levels indicated in the scientific literature, for similar circumstances. Moreover, after this comparison, we intend to discuss the possible effects of microwave constant use on humans and the actual context in the legislation and scientific literature available. 


\section{Experimental part}

\section{Materials and methods}

We used a Radio Frequency EMF Strength Meter, EXTECH with a Frequency Range: $10 \mathrm{MHz}-8 \mathrm{GHz}$ in order to measure the exact level of radiation (electric field, magnetic field and radiation intensity) a microwave oven exerts both when in action and at rest. Our study is focused on three different types of microwave ovens noted in our study as it is shown in table 1 - with numbers 1,2 , and 3 , due to ethical reasons. All microwave ovens used in this study show no sign of intense usage and are functional with no trace of damage. The specifications of these microwave ovens are listed in table 1 , as their manufacturers indicated.

Table 1

SPECIFICATIONS OF THE MICROWAVE OVENS USED

\begin{tabular}{|c|c|c|c|}
\hline $\begin{array}{c}\text { Microwave } \\
\text { oven }\end{array}$ & $\begin{array}{c}\text { Input } \\
\text { (W) }\end{array}$ & $\begin{array}{c}\text { Output } \\
\text { (W) }\end{array}$ & Microwave frequency (Hz) \\
\hline 1 & 1200 & 700 & 2450 \\
\hline 2 & 1150 & 700 & 2450 \\
\hline 3 & 1100 & 700 & 2450 \\
\hline
\end{tabular}

First, we determined through different methods the place where the highest radiation level was present, performing measurements in the front, in the back, and on each side of the oven. Moreover, we have performed registration of power densities in front of the microwave oven when in function, at a distance of $5 \mathrm{~cm}$ at different moments after the oven was started: at the moment we turned it on, after $5 \mathrm{~min}$ of functioning, and after $10 \mathrm{~min}$ of functioning. At rest, the determinations were performed at $5 \mathrm{~cm}$ in front of the oven in the following order: before turning on the oven, immediately after turning the oven off, and at 5, 10, and 15 min after the oven was turned off.

Measurements were made in such conditions that we recreate indoor conditions found in most houses, thus we did not use a special room (e.g. Faraday cage) in order to isolate the microwave oven. The temperature indoor at the moment of measurements was between $20.5^{\circ} \mathrm{C}$ and $21.5^{\circ} \mathrm{C}$. All measurements were performed using the same technique and the same working algorithm, registering the maximum values of power density, the electric and magnetic field. Each measurement was made in triplicate, and the average value for each determination was considered for further discussions. All values were processed using Microsoft Excel 2013.

\section{Results and discussions}

The obtained data show that the highest value for the electric field $(24.03 \mathrm{~V} / \mathrm{m})$ was registered in the front of microwave oven, with differences from one oven to another (fig. 1).

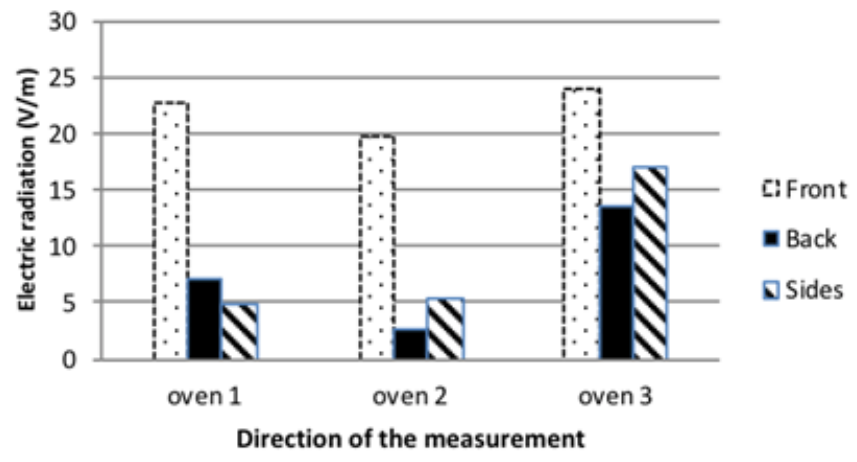

Fig. 1. Electrical field measured in front, sideways, and in the back for the three ovens (ovens turned on)
The magnetic field was also determined during functioning of the microwave oven and the highest value obtained was the one in front of the oven: $63.79 \mathrm{~mA} / \mathrm{m}$ for oven 3 (fig. 2).

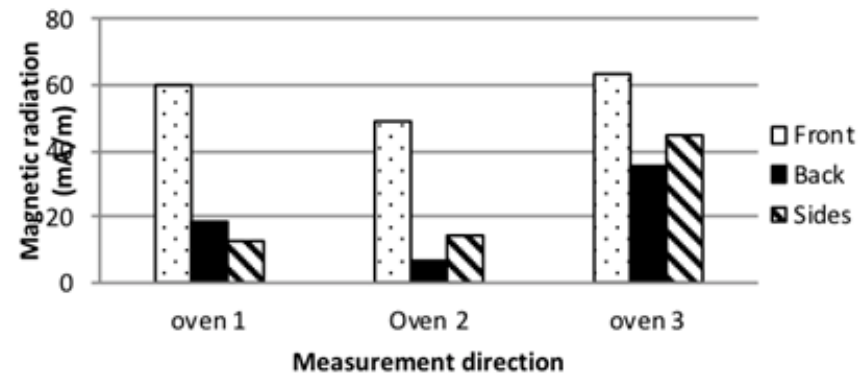

Fig. 2. Measurements of the magnetic field in front, sideways, and in the back of the three ovens, during the function of the microwave ovens

When we compared the value of the magnetic field of the microwave oven when at rest and during the working time we noticed that, at $1 \mathrm{~m}$ away from the oven, the values obtained during function are equal to those at rest. The highest value of the power density was reached after 10 min of functioning of the microwave 1 . The highest values obtained for the power density were registered at $5 \mathrm{~cm}$ in front of the ovens, the distance determining a decrease of these values that tend to equalize the values registered outside working hours at the distance of $1 \mathrm{~m}$ (fig. 3).

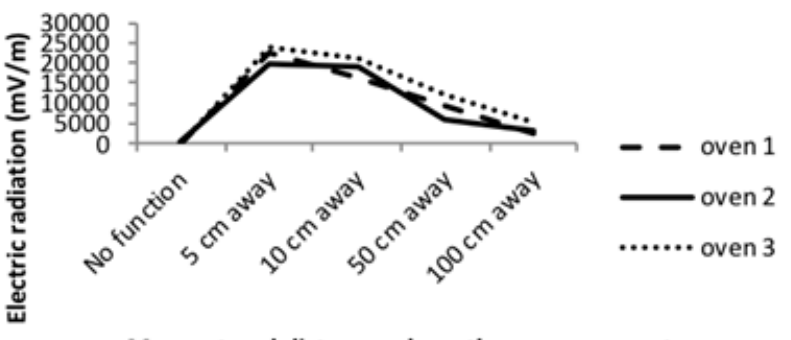

Moment and distance where the measurement were taken

Fig. 3. Level of the power density at different distances from the door of the microwave oven during functioning and in stand by

There has been also measured the magnetic field and it was observed that after 10 min of functioning the ovens generally tend to maintain a plateu of at least $88.27 \%$ of the value registered immediately after turning on the microwave oven (fig. 4).

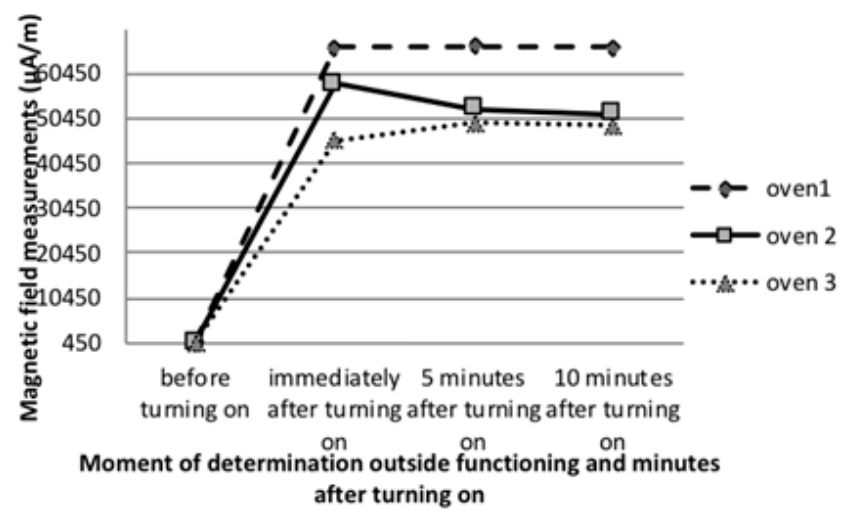

Fig. 4. Magnetic field measured during working programme $5 \mathrm{~cm}$ in front of the ovens at different moments

After swicthing off the microwave ovens we can notice a drop in the values of the magnetic field, but only after 15 minutes their leveles reaching those determined before turning on the ovens (fig. 5). There were measured the electric field while the ovens w ere plugged in, both during 


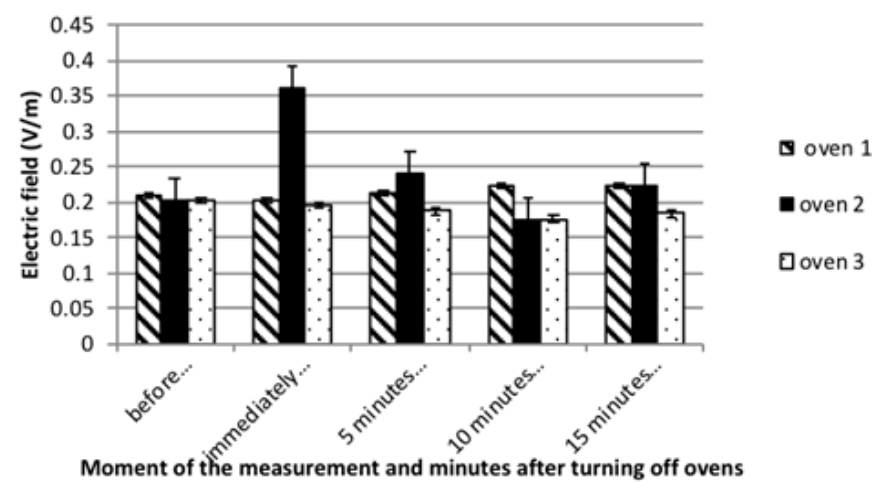

Fig. 5. Electrical radiation values before turning on the ovens and after turning them off (ovens plugged in)

working programme and outside working programme. It can be observed in figure 5 that the electric field tended to reach the values registered before turning on the ovens only after $10 \mathrm{~min}$ of pause. Analyzing the obtained data, it can be noticed that, outside the working hours of the microwave ovens, there is still an electric field with a mean value of $191 \mathrm{mV} / \mathrm{m}$ - value reached after $10 \mathrm{~min}$ of pause.

Further on, we can observe that on average, 5 min after switching off a microwave oven there is still a magnetic field of roughly $544 \mu \mathrm{A} / \mathrm{m}$ that decreases to $515 \mu \mathrm{A} / \mathrm{m}, 5$ min later (fig. 6). We obtained this values after calculating the average magnetic field before turning on, immediately after turn off, 5 and $10 \mathrm{~min}$ after turn off, $5 \mathrm{~cm}$ in front of the three microwave ovens.

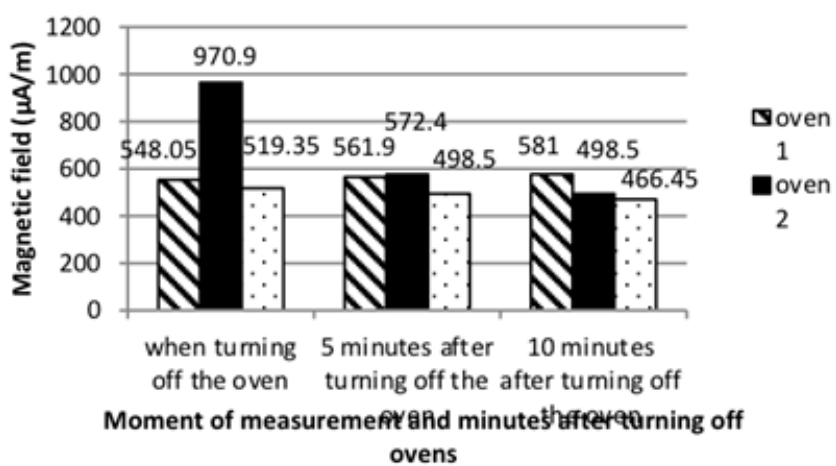

Fig. 6. Magnetic field measured after turning off the microwave ovens $5 \mathrm{~cm}$ in front of the ovens, at different moments

Referring to the electromagnetic field influence on humans, there should be mentioned that depending on the exposure time, distance between the body and the products that emits radiation, there are a series of effects on the human body. Mostly, the scientific literature mentions electric shock, burns and other injuries that appear when high doses affect humans but little is known about constant exposure to low and very-low doses of electromagnetic radiations [18]. The problem of an electromagnetic hypersensitivity emerged from our day-to-day life enhanced with all types of electromagnetic field sources. Both official sites of Canada and World Health Organization (WHO) mention this state as connected to the electromagnetic fields but there is no basis to link it to the electromagnetic field exposure [19]. Whereas Canada finds as a source of electromagnetic fields household electrical appliances among others, WHO only identifies as sources of electromagnetic fields the following ideo display units (VDUs) associated with computers, mobile phones and their base stations [20].

During our determinations, we can notice the amount of electromagnetic radiation that can be absorbed when a human is situated near a microwave oven. All domestic microwave ovens use the same frequency (2450 MHz), not interfering thus with other frequencies, mainly those used in communication. The interesting aspect, when dealing with microwave oven, is the place where many of these products are placed. Mostcommon, these appliances are being places in the kitchen, on counters, or on suspended furniture items, being thus prone to being in very close proximity of the human body at all times: both during function and outside functioning time. Because standards of functioning are the best protocols that give information on devices that have legal permission to be on the market, we have tried to confront our data with the one found in different countries on this issue.

We compared the values we obtained with the data given by the Canadian standards of functioning and USA performance standards for microwave ovens [17,21]. As both documents mention the value of $5.0 \mathrm{~mW} / \mathrm{cm}^{2}$ at all points at least $5 \mathrm{~cm}$ away from the microwave oven with a described test load, we have compared our data to this limit. The test load described must consist of $275 \pm 15 \mathrm{~mL}$ of water at an initial temperature of $20 \pm 5 R$ "C. The probe used in our study meets the criteria mentioned in the description of the functioning standard. Our results show that, during working time, the recommended limit of 5.0 $\mathrm{mW} / \mathrm{cm}^{2}$ is respected, as shown in figure 7.

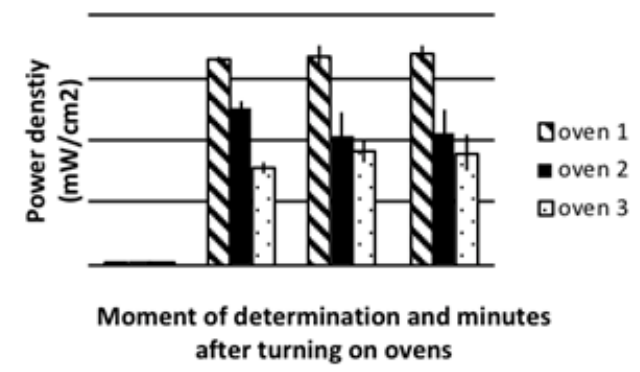

Fig. 7. Measurements of the radiation leakage compared to the standards for Canada and USA

Outside the working time of the microwave ovens, our study shows values insignificantly smaller than those determined during functioning time as shown in figure 8.

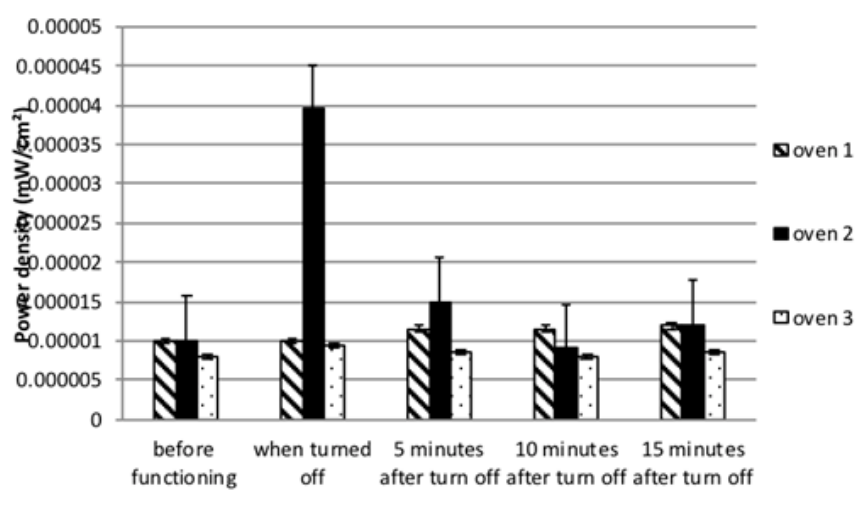

Fig. 8. Radiation leakage measured outside functioning at different moments

Further on, consistent to data studied from the scientific literature [16] the electric field decreases with distance. As seen in the Figure 9, during working time, the electric field decreases with distance, the greatest value registers at $5 \mathrm{~cm}$ in front of the microwave ovens.

To properly analyze the facts, it is important to know how one of the most important appliances that use this type of non-ionizing radiation works. The food in the oven is cooked or heated by exposing it to microwaves. In this way, the polar molecules in the food rotate and thermal energy is produced [2,22]. The way microwaves interact 


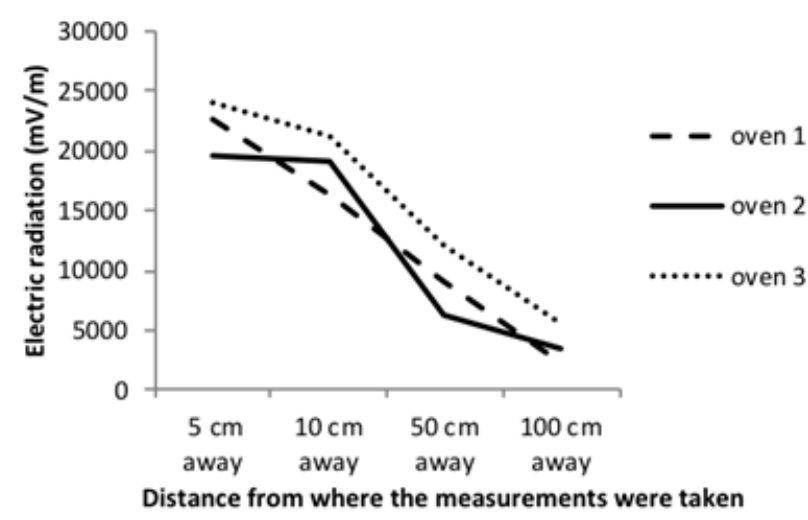

Fig. 9. Electric field measurements during functioning time, at different distances in front of the microwave ovens

with the food inserted into the microwave oven highly depends on the state of the matter inserted. The water content of the food inserted in the microwave oven is an important factor that determines the rate of heating, but the salt content has an impact as well. It is well known that the charged $\mathrm{Na}^{+}$and $\mathrm{Cl}^{-}$ions react too with the alternating electric field leading to movements of the ions that further on determine heat. Thus, the salty foods heat more rapidly that the unsalted one [15].

Inserting a rotating turntable in the cooking chamber of a microwave oven partially solved the problem on nonuniform distribution of heat during usage. Partially because the heat distribution when microwave ovens are used, is still not uniform surging the possibility of not being able to destroy all microorganisms. This effect further on leads to safety issues due to the fact that microorganism which were not destroyed, originated from the places that remained cold, may affect the health of the people using the microwave oven $[23,24]$.

On the problem related to the electromagnetic pollution associated with microwave ovens, this should be mentioned that the microwave oven is built as a Faraday cage, but an imperfect one, since one of its walls is usually made of glass [15]. Despite the fact that usually there are some traps used at the level of the door in order not to allow any radiation leakage, the ovens are not perfect traps of radiation. The proof that there is radiation going out and into the microwave oven is clear when inserting a cell phone into a switched off microwave oven. The cell phone will ring if called, thus showing that the hypothesis that microwave ovens are not perfect radiation traps stands [15].

Among other effects of microwave on biological tissues, we can mention the appearance of cataract, and the microwave hearing effect. There are studies that state that long-time exposure to low-frequency radiation can cause diverse pathologies, this being the reason why Russia adopted even lower safe limits than those adopted by Canada and USA of respectively $1 \mathrm{~mW} / \mathrm{cm}$ [25-27]. Most of the effects that appear when a person is exposed for a long period of time to low and very low frequecy radiation consist of dizziness, fatigue, headache, all of which being not permanent [27].

As 2016 Review on Radiofrequency and health mentions, all devices around us emits simultaneously electromagnetic fields [28]. All the surrounding devices contribute to our daily dose of radiation exposure and represent a certain percentage of this dose. From the baby monitor to the Wi-fi router, and from the cell-phone to the microwave oven, all around us there are devices that expose us to electromagnetic radiation [19,28-31]. Altough the microwave oven emits only $1.49 \%$ of the instantaneous peak power density level of the ICNIRP general population exposure limit among the other devices, the cumulative effect of this exposure needs to be studied more in order to identify all sources of radiation [28,32].

\section{Conclusions}

Our study found safe limits of microwave oven radiation leakages during functioning time as describes by the functioning standards of different countries. In this regard, we recommend the usage of unharmed devices, fully functional, and reduction of the usage time. Moreover we discourage spending time in the near vecinity of a functioning microwave oven.

\section{References}

1.G. BRODIE: Applications of Microwave Heating in Agricultural and Forestry Related Industries. In: The Development and Application of Microwave Heating. Ed. by Wenbin Cao, InTech., 2012.

2.SAXENA, V. K., CHANDRA, U., Microwave Synthesis: a Physical Concept, in Microwave Heating, Ed. Usha Chandra, InTech., 2011. https://www.intechopen.com/books/microwave-heating/microwavesynthesis-a-physical-concept accessed in July 30, 2017.

3.SISODIA, M. L., Microwaves: Introduction to Circuits, Devices and Antennas, New Age International (P) Ltd., New Delhi, 2004.

4.AZAM, S., WAHAB, Q., The Present and Future Trends in High Power Microwave and Millimeter Wave Technologies. In Advanced Microwave and Millimeter Wave Technologies Semiconductor Devices Circuits and Systems, Ed. by Moumita Mukherjee, 2010. https:// www.intechopen.com/books/advanced-microwave-and-millimeterwave-technologies-semiconductor-devices-circuits-and-systems/thepresent-and-future-trends-in-high-pow er-microwave-and-millimeterwave-technologies accesed in Aug. 30, 2018.

5.BUNGAU, C., PANCU, R., BUIDOS, T., Contributions to the Design of the Load Station Concept used at the Flexible Manufacturing Cell. In: Applied Mechanics and Materials, IManE Conference, Chisinau, Moldova, 657, 2014, p. 818.

6.IONESCU, G., RADA, E.C., CIOCA, L.I., Conference: 10th International Conference on Environmental Legislation, Safety Engineering and Disaster Management ELSEDIMA, Cluj-Napoca, Romania, 14, nr. 11, 2015, p. 2537.

7.PRADA, M.F., POPESCU, D.E., BUNGAU, C., Building Education, Source of Energy Saving in Romania. In: Proc. of the 15th National Technical-Scientific Conference on Modern Technologies for the 3rd Millennium, Oradea, Romania, 2016, p. 157.

8.PRADA, M., POPESCU, D.E., BUNGAU, C., PANCU, R., BUNGAU, C., J. Environ. Prot. Ecol., 18, nr. 3, 2017, p. 1425.

9.POPESCU, D.E., BUNGAU, C., PRADA, M., DOMUTA, C., BUNGAU, S., TIT, D.M., J. Environ. Prot. Ecol., 17, nr. 3, 2016, p. 1011.

10.VESSELENYI, T., BUNGAU, C., HUSI, G., Research equipment and computation techniques for Intelligent Building applications. In: IEEE/ SICE International Symposium on System Integration (SII), Tokyo, Japan, 2014, p. 228

11.MERYL, R.T., MCELHNNY, M.W., The Earth's magnetic field: Its history, origin and planetary perspective. International Geophysics Series, Ed. by W.L. Donn, Academic Press Inc. (London) Ltd., 32, 1983.

12.0TTO, M., VON MUHLENDAHL, K.E., Internat. J. Hyg. Environ. Health., 210, nr. 5, 2007, p. 635.

13.J OHANSSON, O., Pathophysiol., 16, nr. 2, 2009, p. 157.

14.ADAMS, D.S., LEVIN, M., Cell Tissue Res., 352, nr. 1, 2013, p. 95. 15.VOLLMER, M., Phys. Educ., 39, nr. 1, 2004, p. 74.

16.*** Safety Code. Limits of Human Exposure to Radiofrequency Electromagnetic Fields in the Frequency Range from $3 \mathrm{kHz}$ to 300 GHz. Environmental Health Directorate, Canada, 1999.

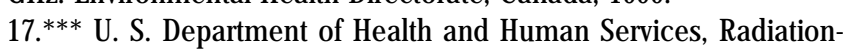
Emitting Products. Microwave Ovens, https://www.fda.gov/RadiationEmittingProducts/RadiationEmittingProductsandProcedures/ HomeBusinessandEntertainment/ucm 116385.htm accessed July 30, 2018. 
18.BANIK, S., BANDYOPADHYAY, S., GANGULY, S., Bioresour. Technol, 87, nr. 2, 2003, p. 155.

19.*** Government of Canada. Health Canada: Environmental and Workplace Health. Radiation. Consumer radiation. Electric and Magnetic Fields. 2011. https://www.canada.ca/en/health-canada/ services/environmental-w orkplace-health/radiation/consumerradiation/electric-magnetic-fields/electromagnetic-hypersensitivityconsumer-radiation.html accessed in July 10, 2018.

20.** WHO. Electromagnetic fields and public health. Electromagnetic hypersensitivity. http://www.who.int/peh-emf/publications/facts/fs296/ en/ accessed in Aug. 31, 2018.

21.*** U. S. Department of Health and Human Services, Performance standards for microwave and radiofrequency emitting products, https:/ /www.accessdata.fda.gov/scripts/cdrh/cfdocs/cfcfr/CFRSearch.cfm? CFRPart=1030 accessed in July 30, 2018.

22.IBRAHIM, G.E., EL-GHORAB, A.H., EL-MASSRY, K.F., OSMAN, F., Effect of microwave heating on flavour generation and food processing. In: The Development and Application of Microwave Heating. Ed. by Wenbin Cao, InTech., 2012.

23.VADIVAMBAL, R., JAYAS, D., Food Bioproc. Tech., 3, nr. 2, 2010, p. 161.

24.HAMCHONG, M., DATTA, A.K., J. Microw. Power Electromagn. Energy, 34, nr. 1, 1999, p. 9.

25.*** IEEE Standards Coordinating Committee: IEEE standard for safety levels with respect to human exposure to radio frequency electromagnetic fields, 3kHz to $300 \mathrm{GHz}$. IEEE C95, 1992. http:// emfguide.itu.int/pdfs/C95.1-2005.pdf accessed in April 17, 2018.
26.THOMAS, S., Understanding the parasitic effects on the microw ave interferences at hearing instrument level up to $6 \mathrm{GHz}$., Master's Thesis, Lund University, 2016, http://www.eit.lth.se/sprapport.php?uid=875 accessed July 22, 2017.

27.DATTA, P.K., Sci. Cult., 81, nr. 3-4, 2015, p. 81.

28.** BC Centre for Disease Control, National Collaborating Centre for Environmental Health, 2016 Review: Radiofrequency and Health. 2016. available from: http://www.bccdc.ca/resource-gallery/ Documents/Guidelines\%20and\%20Forms/Guidelines\%20and\%20 Manuals/EH/RPS/BCCDC\%20RF\% 20Health \%2OReport.pdf accessed in May 20, 2018.

29.CIOCA L.I., MORARU, R.I., BABUT, G.B., The $15^{\text {th }}$ International Conference-The Knowledge-Based Organization, 2009, Sibiu, Romania, 2, p. 44.

30.CIOCA L.I., MORARU R.I., Manag. Sustainable Develop., 2, nr. 2, 2012, p. 71.

31.CIOCA, M., CIOCA, L.-I., DUTA, L., Web technologies and multicriteria analysis used in Enterprise integration, studies in informatics and control, 20, nr. 2, 2011, p. 129.

32.*** International Commission on Non-lonizing Radiation Protection: ICNIRP statement on the Guidelines for limiting exposure to timevarying electric, magnetic, and electromagnetic fields (up to $300 \mathrm{GHz}$ ). Health Phys, 97 (3), 257 (2009). http://www.icnirp.de/documents/ RFReview.pdf accessed in J anuary 28, 2018.

Manuscript received: 19.12 .2018 